\title{
1 Milk losses linked to udder health treatments at dairy farms with automatic milking systems
}

2 Ines Adriaens, ${ }^{\mathrm{a},}$, Igor Van Den Brulleb, Ben Aernoutsa

3 a KU Leuven, Department of Biosystems, Division of Animal and Human Health Engineering,

4 Campus Geel, Kleinhoefstraat 4, 2440 Geel, Belgium. ines.adriaens@kuleuven.be;

5 ben.aernouts@kuleuven.be

$6 \quad \mathrm{~b}$ Ghent University, Department of Reproduction, Obstetrics and Herd Health, M-team and Mastitis

7 and Milk Quality Research Unit, Salisburylaan 133, 9820 Merelbeke, Belgium.

$8 \quad$ igor.vandenbrulle@ugent.be

$9 \quad{ }^{*}$ Corresponding author: Ines Adriaens, ines.adriaens@kuleuven.be, Kasteelpark Arenberg 30 box

10 2456, 3001 Leuven, Belgium +32 (0) 16328873

11

\section{Highlights}

- Milk losses were estimated for treated cases of intramammary infections

- $\quad$ Milk losses were highly variable across cases with a median of $101 \mathrm{~kg}$

- We found large differences between infected and non-infected quarters

- Quantification of milk losses can be the basis for better udder health management

\section{Abstract}

19 Milk losses caused by intramammary infections (IMI) have a massive impact on farm profitability

20 and sustainability. In this study, we analyzed milk losses from 4553 treated IMI cases at 41 AMS

21 dairy farms. Milk losses were estimated based on the difference between the expected and the true

22 production. To estimate the unperturbed lactation curve, we applied an iterative procedure using

23 the Wood model and a variance-dependent threshold on the milk yield residuals. We calculated 
24 milk losses both in a fixed window around the first treatment day of each IMI case and in the

25 perturbations corresponding to this day, at cow level as well as at quarter level. In a fixed time

26 window of day -5 to 30 around the first treatment, the absolute median milk losses per case were

$27101.5 \mathrm{~kg}$, highly dependent on the parity and the lactation stage with absolute milk losses highest in

28 multiparous cows and at peak lactation. Relative milk losses expressed in percentage were highest

29 on the treatment day, and full recovery was often not reached within 30 days from treatment onset.

30 In $62 \%$ of the cases, we found a perturbation in milk yield at cow level at the time of treatment. On

31 average, perturbations started 8.7 days before the first treatment and median absolute milk losses

32 increased to $128 \mathrm{~kg}$ milk per perturbation. Mastitis is not expected to have equal effects on the four

33 quarters so this study additionally investigated losses in the individual udder quarters. We used a

34 data-based method leveraging milk yield and electrical conductivity to project the presumably

35 infected quarter and compared losses with the average of presumably non-infected quarters.

36 Median absolute losses in a fixed 36-day window around treatment varied between $50.2 \mathrm{~kg}$ for

37 front and $59.3 \mathrm{~kg}$ for hind infected quarters compared to respectively 24.7 and $26.3 \mathrm{~kg}$ for the

38 median losses in the non-infected quarters. Also here, these losses depended on lactation stage and

39 parity. Expressed proportionally to expected yield, the relative median milk losses in infected

40 quarters on the treatment day were $20 \%$ higher in infected quarters with a higher variability and

41 slower recovery. In $86 \%$ of the treated IMI cases, at least one perturbation was found at the quarter

42 level. This analysis confirms the high impact of IMI on milk production, and the large variation

43 between quarter losses illustrates the potential of quarter analysis for on-farm monitoring at farms

44 with an automated milking system.

\section{$45 \quad$ Key words}

46 milk loss; intramammary infection; quarter milk yield; modelling; automated milking system;

47 mastitis 

sustainability, having significant impact on animal welfare, efficiency of production and milk

52 compared to conventionally milking operations, the impact of IMI is even higher at AMS farms

53 (Barkema et al., 2015; Deng et al., 2020).

54 Quantification of milk losses and milk yield dynamics raises the farmers' awareness of the impact of

55 IMI on a factual basis. This lays the groundwork for improved detection and treatment decisions, as

56 such limiting their negative impact. In the past, most studies either used low frequency data to

57 study these milk losses, or relied on experimental infections limiting the number and

58 representativeness of IMI cases included (Gröhn et al., 2004; Bar et al., 2008). A solution is to

59 analyze the impact of IMI based on commercial farms' treatment registers and milk meter data.

60 Unfortunately, high-quality datasets comprising both treatment records and high-frequency on-

61 farm milk meter data are scarce. Reliability of treatment registers, moreover, is often hampered due

62 to poor registration by farmers, both in quality and quantity (Stevens et al., 2016), while only in the

63 past decennia high-frequent milk production data became more frequently available on farm. The

64 latter has tremendously improved with the increased use of AMS that record and store milk yield

65 per milking as well as per quarter in an automated way.

66 With high-frequency milk production time series available, it becomes possible to accurately

67 estimate milk losses associated with health problems. To this end, a good estimation of the

68 expected milk production in absence of perturbations is needed. For example, we (Adriaens et al.,

$692018,2020,2021$ ) and others (Poppe et al., 2020; Ben Abdelkrim et al., 2021) developed

70 methodologies to predict milk yield in an unperturbed state. These predicted trajectories and their

71 corresponding deviations can subsequently be used to study resilience, for improved monitoring 
72 and precision phenotyping as well as for the characterization of milk yield dynamics and losses

73 during challenges. In the case these challenges involve udder health problems, the milk yield of the

744 individual udder quarters can be mutually compared next to studying the cow-level milk yield.

75 Quarter separation additionally provides a unique opportunity to study losses and dynamics in the

76 different quarters separately and to distinguish local (i.e., related to the local inflammatory reaction

77 and toxins) and systemic (i.e., related to the general sickness) effects of the infection (Adriaens et

78 al., 2018).

79 A better quantification of the actual milk losses during IMI provides the necessary knowledge to

80 further raise awareness among farmers and veterinarians on the impact of udder health on farm,

81 and by extension, on dairy production's sustainability through improved profitability and decrease

82 antimicrobial use. Distinguishing between the cow and quarter level additionally leverages new

83 opportunities for better use of available on-farm data for monitoring and decision support. Starting

84 from an elaborate data set that includes both the high-frequency sensor data and treatment

85 registers from modern AMS dairy farms, this study aimed to describe milk losses related to

86 treatments of IMI. To this end, we studied cow and quarter level milk yields and losses both in a

87 fixed period around the first treatment and in perturbations associated with these treatments.

\section{MATERIALS AND METHODS}

Data collection. This study relied on two main sources of data: high-frequency sensor data and

91 udder health treatment registers. For the sensor data, back-up files of the AMS software were

92 collected on 50 modern dairy farms with a Lely ( $\mathrm{N}=20$, Maassluis, The Netherlands) or DeLaval

93 (N=30, Tumba, Sweden) AMS in Belgium and The Netherlands during a farm visit. For DeLaval

94 farms, additional back-ups were downloaded at intervals of 180 to 400 days depending on the AMS

95 software settings. This procedure ensured access to minimal 1 year of uninterrupted longitudinal 
sensor time series for the analysis. During the farm visits, we also copied the treatment registers

97 related to udder health problems. These treatment registers were either handwritten on paper,

98 recorded in a spreadsheet, included in the AMS software or entered in separate farm management

99 software (Unifarm, Uniform-Agri, Assen, The Netherlands).

Editing and selection of sensor data. Raw data tables were exported as flat files from the AMS

101 software back-up files using T-SQL and Microsoft SQL Management Studio (Microsoft, Redmond,

102 USA). The different tables were horizontally (combining cow identification (ID), dates, etc. with the

103 sensor records) and vertically (combining different back-up files of the same farm) merged and

104 further processed using Matlab 2019a (MathWorks, Natick, MA, USA). Per farm, two data sets of

105 sensor data were compiled: one set containing the daily milk production records at cow level

106 (CMY), and a second set containing the sensor data per individual milking at quarter level,

107 including the milk yield (QMY) and electrical conductivity. The first data set of CMY contained

108 records from the installation date of the AMS system onwards for all farms. The daily data coming

109 from DeLaval AMS represent the sum of the milk yields produced each calendar day (i.e. 24 hours),

110 while the Lely AMS software, before storage, corrects for the varying number of milkings per day

111 per cow when milking with AMS. To obtain a similar variance as for the Lely milk production data,

112 the daily milk production time series of DeLaval farms were smoothed with a moving average using

113 a span of 3 days before the analysis (Adriaens et al., 2020). The second data set for Lely AMS

114 systems contained all data since the installation of the AMS and thus matches with the daily data,

115 whereas for DeLaval systems the second data set typically comprised a shorter period compared to

116 the daily data. This is because individual milking information in the DeLaval software is only stored

117 for a limited amount of time, typically 180 or 400 days depending on the software settings. For each

118 farm and each data set, we kept only the lactations with enough data to reliably estimate milk

119 losses. To this end, we selected lactations that started within 5 days after calving (days in milk,

120 DIM) and for which at least 150 days of milk production data were available. Lactations for which 
121 data were missing during more than five successive days were also excluded from the analysis. Only

122 the first 305 days of milk production were considered to avoid the lactation curve being affected by

123 pregnancy or impending dry-off.

124 Expected milk production. To calculate milk losses as the expected versus the actual milk

125 production, first a reliable estimation of the expected production must be obtained. For the CMY

126 analysis, the method described in Adriaens et al. (2021) was used. This is based on an iterative

127 fitting of the Wood model (Wood, 1967) in which records that are part of a perturbation are

128 removed to obtain a fit unaffected by perturbations. For the QMY data, the methodology for

129 estimating the unperturbed lactation trajectory was adjusted to deal with the higher variability in

130 production and to account for the varying milking intervals. To this end, we evaluate the milk yield

131 residual against a threshold of 1.6 times the standard deviation of these residuals as described

132 below. For the QMY, following steps were implemented, visualized in Figure 1:

133 1) Upper panel Figure 1. The QMY was transformed to $Q M Y_{t}$, expressed in kg milk per 24 hours

134 by dividing the QMY by the milking interval and multiplying it by 24 hours (pink circles).

135 The multiplication aids in stabilizing the parameters of the Wood model in the iterative

136 fitting procedure, while the correction for milking interval ensures that the variability

137 caused by different intervals between milkings does not bias the lactation curve shape.

138 2) To correct for outliers with very high milk yields e.g. caused by a failure of the previous milking, the $\mathrm{QMY}_{\mathrm{t}}$ was smoothed with a median smoother (dark grey solid line) on a window of 18 measurements (+/- 2 weeks at a milking frequency of 2.6 milkings per day).

143 estimation of the model in de next steps.

144 3) An initial Wood curve $\left(\mathrm{QMY}_{\mathrm{t}}=\mathrm{a}^{*} \mathrm{DIM}^{\mathrm{b}} * \mathrm{e}^{-\mathrm{c}^{*} \mathrm{DIM}}\right)$ is fitted on all the remaining $\mathrm{QMY}_{\mathrm{t}}$ of the 145 lactation to obtain the initial unperturbed lactation curve $\mathrm{ULC}_{1}$. The residuals from this 
initial model are calculated as QMY-ULC ${ }_{1}$, from which the standard deviation $\left(\mathrm{SD}_{1}\right)$ and the root mean squared error $\left(\mathrm{RMSE}_{1}=\sqrt{\overline{\left(Q M Y_{t}-U L C_{1}\right)^{2}}}\right)$ were computed.

4) $\mathrm{QMY}_{\mathrm{t}}$ below $1.6 * \mathrm{SD}_{1}$ were deleted (orange squares) except when they occurred in the first lactation curve. Accordingly, a new non-linear Wood curve (ULC $\mathrm{C}_{\mathrm{i}}$, orange dashed line) was fitted on the remaining $\mathrm{QMY}_{\mathrm{t}}$. Again, the $\mathrm{QMY}$ for which the residuals were below $1.6 * \mathrm{SD}_{\mathrm{i}}$, but which were not in the first 5 days of lactation were deleted. The RMSE $E_{\mathrm{i}}$ of the remaining residuals was computed.

5) This refitting and deletion iterations were continued until the difference in $\mathrm{RMSE}_{\mathrm{i}}$ between the current and the previous iteration was less than $0.1 \mathrm{~kg}$ of milk.

6) The final model (blue solid line in upper panel) was retransformed, by multiplying it with the milking interval and dividing it by 24 , to obtain the expected milk production for that udder quarter for each milking event (unperturbed lactation curve, ULC $_{F}$, blue solid line in middle panel Figure 1).

161 production. Dividing the absolute milk losses (i.e. kg of milk) by the expected milk yield renders the 162 relative milk losses (\% milk loss, lower panel in Figure 1).

164 Identification of perturbations in milk yield. For this study, we calculated milk losses at cow and quarter level both in a fixed window around the day of the first udder health treatment (treatment day, TD), and in perturbations in which the TD was included. The latter provides additional

167 information on when the deviation in milk yield starts and on its true duration. Perturbations are

168 considered as periods in which the milk production is consistently below the expected milk

169 production. For the CMY data, again similar criteria as in Adriaens et al. $(2020,2021)$ were applied. 
In brief, at cow level, a perturbation was defined as an episode for which the CMY was below the

171 expected yield (ULC ) for at least 5 consecutive days, with at least one day below $80 \%$ of the

172 expected production. These criteria are the result of discussions with veterinary experts and are

173 motivated in Adriaens et al. $(2020,2021)$. For the QMY, the higher variability compared to CMY

174 data needed to be considered. Therefore, perturbations were identified on the 7-day median

175 smoothed relative residuals (Figure 1, lower panel, orange line) rather than the raw data. A

176 perturbation was considered as a period in which (1) the median smoothed residuals were below 0

177 for at least 7 consecutive days, and (2) for which at least 5 milkings were below $80 \%$ of the

178 expected yield (Figure 1, lower panel, red line). Perturbations between individual udder quarters of

179 the same cow were compared and an overlap was identified when the minima of the perturbations

180 were separated in time by less than $50 \%$ of the average length of those perturbations.

Editing of treatment registers and selection of IMI cases. In a first step, all available treatment

183 registers were digitalized and their format standardized to obtain a well-organized list containing

184 at least the animal ID and date for each treatment. Records with no clear ID, no date or that were

185 not related to IMI were deleted. Only the first treatment of the IMI was considered, and records

186 from the subsequent days were removed. If there was a gap of more than 10 days between 2

187 treatments, they were considered as different treated IMI cases, further referred to as IMI cases.

188 Next, the cow IDs of the treatment registers were coupled to the unique cow IDs in the milk yield

189 data sets. Only IMI cases with a TD that occurred within the time span of the available milk yield

190 data and before 305 DIM after calving were kept, because only for these IMI cases the milk losses

191 could be calculated. As the timespan for the CMY data was longer than for the QMY data, the IMI

192 cases included for the analysis of milk losses at quarter level were a subset of those included for the

193 cow-level analysis. Based on the quarter level data (QMY and electrical conductivity), we identified

194 the presumably infected quarter (IQ) to allow comparison of milk losses between the IQ and the 
195 presumably non-infected (NIQ) quarters. To distinguish the IQ from the NIQ, the relative milk

196 losses expressed in \% in each quarter were calculated over a period of 36 days (day -5 to 30 from

197 the TD). Next, following criteria were applied: 1) the IQ is the quarter for which the relative milk

198 losses, expressed in percentage, in the 36-day period was within $1 \%$ difference from the minimum

199 of relative milk losses of the 4 quarters, and 2) the inter quarter ratio of that quarter's electrical

200 conductivity was higher than 1 . This inter quarter ratio per quarter was calculated as the average

201 electrical conductivity of that quarter divided by the average of the other 3 quarters in the first 10

202 days after the TD. As the amount of IMI cases recorded and thus, the reliability of the treatment

203 registers was too variable across the different farms, the data of each farm were not analyzed

204 separately, neither was it possible to make statements on IMI incidence rates or the milk losses at

205 farm level.

207 Milk loss analyses. Milk losses were calculated both in a fixed window of 36 days around the TD

208 (day -5 to day 30) and in perturbations that included the TD. We considered both milk losses

209 expressed in absolute numbers ( $\mathrm{kg}$ milk lost = produced - expected $\mathrm{ULC}_{\mathrm{F}}$ ), further referred to

210 'absolute milk losses' and in relative numbers (\% milk loss, 'relative milk losses'). The calculation of

211 the milk losses in a certain period (fixed window or perturbation) for the QMY data was based on

212 the raw data to account for the true milk yield, and not on the median smoothed data used for

213 detection of perturbations. Because the distribution of the milk losses did not have a Gaussian

214 shape, we report their median, first quartile and last quartile. The milk production dynamics are

215 known to differ across parities and lactation stages (Wilson et al., 2004; Hertl et al., 2014; Heikkilä

216 et al., 2018). Therefore, we report the milk losses in 3 lactation stage classes (LS1: DIM 0 to 20, LS2:

217 DIM 21 to 140 and LS3: DIM 141 to 305) and 2 parity classes (P1: first parity vs. P2: higher

218 parities). For the analyses at quarter level, we distinguished losses in IQ and the average of the NIQ,

219 and we used a paired t-test to compare their level at the different moments relative to the TD. For 
220 the perturbation analysis at quarter level, we considered the milk losses for the duration of the

221 perturbation detected in the IQ for all 4 quarters.

224 Data overview. From the 6299 IMI cases that were identified based on the treatment registers and

225 for which animal IDs were available, 4553 IMI cases overlapped with the CMY data. Only for these

226 we could calculate the milk losses at cow level. These 4553 IMI cases originated from 2387 unique

227 cows, 2999 lactations and 41 farms (25 Delaval, 16 Lely). This means that for the animals that had

228 at least one IMI treatment registered, on average 1.9 IMI cases were recorded, corresponding to 1.5

229 IMI cases per lactation. The time between the first and last treatment of a farm included in the

230 analysis was on average 3.7 years, but the variability between farms was very high, ranging from

231250 days to 14 years. Further information on the number of IMI cases, cows and lactations at farm

232 level is given in Table 1, together with their distribution over lactation stages, parities, and seasons.

233 We had more treatments in July to September compared to the other months, and proportionally

234 more IMI cases in early lactation. With the covered period for QMY data in DeLaval software back-

235 ups being shorter, only 3369 cases from 37 farms (21 DeLaval, 16 Lely), 1882 cows and 2296

236 lactations could be included for the analysis at quarter level. In this data set, we see a similar

237 proportion of IMI cases for parity, lactation stage and season as for the cow-level data set, resulting

238 in a higher percentage of IMI cases treated in the first 20 DIM and in the summer (July to

239 September). 
240 Table 1: Overview of the treated IMI cases that overlapped with the cow-level milk yield (CMY) and the quarter milk yield

241 (QMY) data per farm and the proportion of cases per lactation stage (LS), parity (P) and season over the entire data set.

\begin{tabular}{lcc}
\hline & \multicolumn{2}{c}{ Treated IMI cases } \\
\hline No. of IMI cases (mean \pm SD, [range]) & CMY & $91 \pm 147,[3 ; 790]$ \\
No. of unique cows (mean \pm SD, [range]) & $111 \pm 191,[1 ; 1066]$ & $50 \pm 65,[3 ; 355]$ \\
No. of unique lactations (mean \pm SD, [range]) & $73 \pm 108,[1 ; 582]$ & $62 \pm 488,[3 ; 467]$ \\
Proportion of IMI cases per LS ${ }^{1}$ (\% per day) & & 0.61 \\
$-\quad$ LS1 & 0.66 & 0.38 \\
$-\quad$ LS2 & 0.37 & 0.26 \\
$-\quad$ LS3 & 0.25 & 15.7 \\
Proportion of IMI cases per parity (\%) & 19.3 & 84.3 \\
$-\quad$ P1 & 80.7 & 22.3 \\
$-\quad$ P2 & 22.5 & 23.7 \\
Proportion of IMI cases per season (\%) & 23.1 & 30.5 \\
$-\quad$ January to March & 30.1 & 23.5 \\
$-\quad$ April to June & 24.3 & \\
$-\quad$ July to September & & \\
$-\quad$ October to December & &
\end{tabular}

244 Table 2 gives an overview of the milk production characteristics of the included farms, calculated

245 from all lactations for which data of at least the first 150 DIM were available. Because the period for

246 which data were available varied across farms (e.g. for some farms only 1 or 2 years of data could

247 be included, limiting the amount of selected lactations), this is not an exact representation of the

248 farm characteristics, but it rather represents the data composition at farm level used for the

249 analysis.

251 Table 2. Overview of the farm characteristics for the cow-level (CMY) and quarter milk yield (QMY) data sets in the

252 period covered by the treatment registers

\begin{tabular}{lcc}
\hline & CMY & QMY \\
& mean \pm SD, [range] & mean \pm SD, [range] \\
\hline No. of unique cows & $409 \pm 773,[26 ; 5079]$ & $262 \pm 203,[26 ; 1036]$ \\
No. of lactations & $704 \pm 935,[26 ; 5656]$ & $510 \pm 491,[26 ; 2748]$ \\
Covered time period (days) & $1390 \pm 1126,[255 ; 4970]$ & $1023 \pm 878,[203 ; 4605]$ \\
Average daily milk yield (kg) & $32.2 \pm 3.7,[22.3 ; 43.6]$ & -- \\
Average per milking yield (kg) & --- & $11.8 \pm 1.4,[8.7 ; 14.8]$ \\
Average 305-day milk yield (kg) & $9856 \pm 1147,[6784 ; 13411]$ & $10105 \pm 1045,[7557 ; 13399]$ \\
Milking frequency (milkings/day) & --- & $2.8 \pm 0.24,[2.2 ; 3.3]$ \\
\hline
\end{tabular}




\section{Milk losses at cow level}

256

257

258

259

260

261

262

263

264

265

266

267

268

269

270

271

272

273

274

275

276

277

278

Milk losses in a fixed window around treatment. We found that on average, milk losses between

TD -5 to TD +30 summed up to $164 \pm 204 \mathrm{~kg}$ per IMI case (mean \pm SD), while the median milk losses were $101 \mathrm{~kg}$ and the 25 and 75 percentiles were 38 and $215 \mathrm{~kg}$. Table 3 gives the absolute milk losses in a fixed window of TD -5 to TD +30 , whereas Figure 2 presents the relative losses per day, split per parity and lactation stage class (right, P1; left, P2; up to down LS1 to LS3). Table 3 and Figure 2 show that none of the distributions have a Gaussian shape, but they are skewed with a mode smaller than the medians and means and a heavy tail towards higher losses. For example, for the absolute milk losses in the fixed window around the TD, the mode was $69 \mathrm{~kg}$, while the median and mean were respectively 101 and $164 \mathrm{~kg}$ milk, implying that proportionally more IMI cases had smaller losses and a small number of IMI cases had extremely high milk losses. From Table 3, it can be concluded that the absolute milk losses increase with lactation stage in first parity cows. In higher parity cows, the absolute milk losses for IMI cases treated between day 21 to 141 were higher than in the early or late lactation stages. The absolute milk losses were lower in first parity cows compared to higher parity cows. In the early and late LS, the milk losses were about equal across parities. In $76.1 \%$ of the IMI cases, there were milk losses registered in the 5 days before TD, resulting in median milk losses of $11 \mathrm{~kg}$ in the 5 days before TD considering all parities and lactation stages together. Only for IMI cases detected in the first 20 DIM of $2^{\text {nd }}$ and higher parity cows (P2, LS1), more than $25 \%$ of the IMI cases had no losses before treatment. The milk losses in the days after TD reflect the severity and recovery rate of the IMI cases. Overall, median milk losses add up to $75.6 \mathrm{~kg}$ milk in the 30 days after the TD. However, mainly IMI cases in the first 20 DIM seem to give less milk losses, as no milk losses were found when considering the entire 30-day period after TD in more than $25 \%$ of the IMI cases. Also here, the absolute losses were highest for higher parity cows in the second lactation stage (DIM 21-140). 
Figure 2 shows that in all lactation stage and parity classes a clear perturbation is present around

the TD. Relative milk losses increase with lactation stage for both parity classes and in most classes

the median relative losses do not reach 0 within 30 days after the TD. However, for first parity IMI

Table 3. Absolute milk losses in a fixed window of 36 days around the first treatment day (TD) calculated from cow-level

290 and thus in positive numbers.

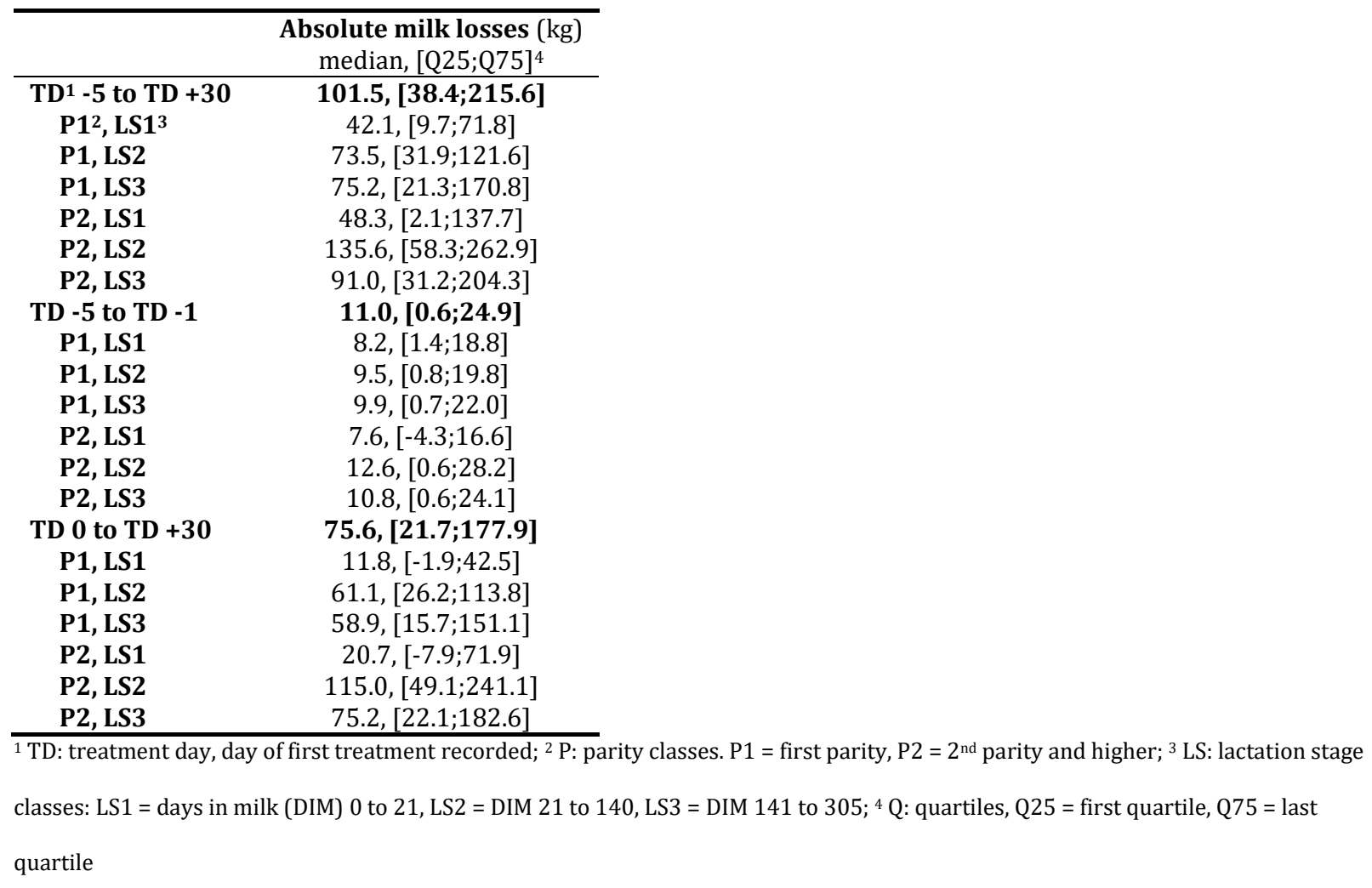


Milk losses in perturbations. Because of the high variability in milk losses across IMI cases, we also analyzed the true impact of IMI on CMY based on the milk yield perturbations including the TD. As we set criteria for what was considered a perturbation, this part of the analysis is biased towards more severe IMI cases, but it considers the true duration of the IMI cases' impact. A perturbation was found in 2823 out of the 4553 cases (62.0\%), which means that for $38.0 \%$ of treatments CMY did not drop below $80 \%$ of the expected yield for at least one day, or the perturbation was shorter than 5 days. The length of the perturbations (Figure 3) varied between 5 and 190 days. Overall, shorter perturbations were more often identified in early lactation compared to later lactation stages. Over all parities, 91,52 and $60 \%$ of the perturbations were 30 days or shorter (red vertical

304 line in Figure 3) when the TD was in LS 1, 2 or 3 respectively. The perturbations started on average $8.7 \pm 12.9$ days before treatment, with the mode (most frequent value, $15.1 \%$ ) being 1 day before treatment, demonstrating again the highly variable effect of IMI on milk yield. higher than when using a fixed window $(101 \mathrm{~kg})$. When comparing milk losses across lactation

310 stages and parities, the same trends as for the milk losses in the fixed window around TD were

311 observed (Table 4). Absolute milk losses in the first parity were lower than in higher parities.

312 Moreover, in the first parity, they increased with lactation stage, whereas in higher parities for mid-

313 lactation TD (LS 2, P2), they were highest with median milk losses of $179 \mathrm{~kg}$. When the relative milk

314 losses are considered, the difference between parities and lactation stages almost entirely

315 disappears. Over all parities and lactation stages, the median relative milk losses were 17.2\%, with

316 the first and last quartile respectively 12.9 and 23.2\%. Similar results are found for each of the P

317 and LS classes, with only milk losses in late lactation higher for both parities (respectively 17.2 and

$318 \quad 18.7 \%$ ). 
319 Table 4. Absolute and relative milk losses in perturbations at cow level corresponding to cases of intramammary

320 infections. The milk losses are expressed as the amount of milk lost, and thus in positive numbers.

\begin{tabular}{lll}
\hline & $\begin{array}{l}\text { Absolute milk losses (kg) } \\
\text { median, [Q25;Q75] }\end{array}$ & $\begin{array}{l}\text { Relative losses (\%) } \\
\text { median, }[\mathrm{Q} 25 ; \mathrm{Q} 75]\end{array}$ \\
\hline Overall $^{3}$ & $\mathbf{1 2 8 . 0},[59.2 ; 296.5]$ & $\mathbf{1 7 . 2},[12.9 ; 23.2]$ \\
P1 $^{1}, \mathbf{L S 1}{ }^{2}$ & $37.9,[26.2 ; 69.6]$ & $16.2,[12.6 ; 22.5]$ \\
P1, LS2 & $110.9,[58.6 ; 211.9]$ & $15.4,[11.9 ; 19.8]$ \\
P1, LS3 & $118.8,[59.5 ; 237.0]$ & $17.2,[13.0 ; 23.5]$ \\
P2, LS1 & $59.3,[34.2 ; 108.9]$ & $16.0,[12.3 ; 20.9]$ \\
P2, LS2 & $176.4,[83.9 ; 386.6]$ & $16.6,[12.3 ; 22.1]$ \\
P2, LS3 & $128.3,[57.6 ; 278.7]$ & $18.7,[14.1 ; 25.9]$ \\
\hline
\end{tabular}

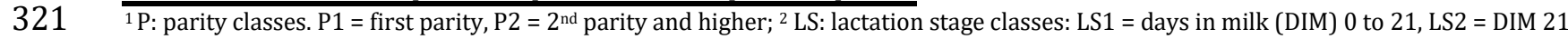

322 to $140, \mathrm{LS} 3=\mathrm{DIM} 141$ to 305 ; $^{3} \mathrm{Q}$ : quartiles, Q25 = first quartile, Q75 = last quartile

\section{Milk losses at quarter level}

Milk losses in a fixed window around treatment. From the 3369 IMI cases with QMY data

were considered for the analysis as they allowed for comparing milk losses between the IQ and the average of the NIQ. From these, the IQ was the left front, right front, left hind and right hind quarter in respectively 558 (25.5\%), 559 (25.5\%), 520 (23.7\%) and 553 (25.3\%) IMI cases. This suggests that there is no difference between front or hind quarters in their probability of being infected. For some of the treatment registers, we had information available on the infected quarter as registered

334 cases with the quarter identified by the farmer.

335 Table 5 presents the absolute milk losses (in $\mathrm{kg}$ ) in a fixed window around the TD, separately for

336 IMI cases in which the IQ was a front quarter or a hind quarter. The average absolute milk losses of

337 the NIQ for which IQ was a front quarter includes one front (lower milk yield) and two hind

338 quarters and vice versa. As a result, the median absolute milk losses for front IQ are lower than for

339 hind IQ, and the other way around for the NIQ. Both for front and hind IQ, overall absolute milk

340 losses in the IQ are larger than on average in the NIQ, and this remains true before the TD as well as 
341 after the TD, and in all parity and LS classes. Milk yield starts to drop already before the TD in all

342 quarters, but this is more pronounced in the IQ. Furthermore, when analyzing the differences

343 between lactation stages and parities of the IQ, we see similar trends as for the CMY. Milk losses in

344 the IQ are lower in the first lactation stage compared to later stages. There was nearly no difference

345 between the absolute losses in LS2 and 3 in the first parity class, but for IMI cases in higher parities,

346 milk losses in LS2 were clearly higher than those in LS3 for both front and hind IQ. The milk losses

347 in the respective periods before and after the TD are further detailed Table 5.

Table 5. Absolute milk losses at quarter level, for which the presumably infected quarter (IQ) was either a front or a hind

\begin{tabular}{|c|c|c|c|c|}
\hline & \multicolumn{2}{|c|}{$\begin{array}{c}\text { IQ }^{5}=\text { front quarter } \\
\text { median, }[\mathrm{Q} 25 ; \mathrm{Q} 75]^{4}(\mathrm{~kg})\end{array}$} & \multicolumn{2}{|c|}{$\begin{array}{c}\text { IQ }=\text { hind quarter } \\
\text { median, }[\mathrm{Q} 25 ; \mathrm{Q} 75]^{4}(\mathrm{~kg})\end{array}$} \\
\hline & IQ & Average of NIQ 6 & IQ & Average of NIQ \\
\hline TD $^{1}-5$ to $\mathrm{TD}+30$ & $50.2,[24.2 ; 83.5]$ & $24.7,[8.7 ; 52.3]$ & $59.3,[28.7 ; 104.6]$ & $26.3,[9.6 ; 49.0]$ \\
\hline $\mathrm{P} 1^{2}, \mathrm{LS}^{3}{ }^{3}$ & $20.8,[11.0 ; 38.8]$ & $15.4,[6.8 ; 35.9]$ & $25.2,[9.6 ; 38.1]$ & $15.4,[3.2 ; 26.3]$ \\
\hline P1, LS2 & $36.8,[15.6 ; 65.2]$ & $23.2,[11.2 ; 36.4]$ & $58.9,[29.0 ; 96.5]$ & $26.6,[13.9 ; 42.5]$ \\
\hline P1, LS3 & $36.0,[21.2 ; 70.6]$ & $11.8,[1.1 ; 28.0]$ & $56.1,[25.7 ; 97.3]$ & $23.7,[6.0 ; 45.3]$ \\
\hline P2, LS1 & $25.5,[11.5 ; 53.7]$ & $14.2,[3.8 ; 42.7]$ & $29.3,[13.3 ; 55.6]$ & $19.2,[5.7 ; 36.4]$ \\
\hline P2, LS2 & $61.2,[37.2 ; 98.8]$ & $36.7,[18.4 ; 63.7]$ & $73.4,[44.2 ; 135.5]$ & $37.0,[17.5 ; 62.2]$ \\
\hline P2, LS3 & $46.4,[20.9 ; 83.4]$ & $18.7,[2.8 ; 45.2]$ & $57.3,[29.5 ; 102.6]$ & $21.0,[4.7 ; 41.9]$ \\
\hline TD -5 to TD -1 & $3.8,[0.09 ; 8.9]$ & $3.7,[0.82 ; 8.2]$ & $4.1,[-0.25 ; 11.1]$ & $3.8,[0.85 ; 8.1]$ \\
\hline P1, LS1 & $1.4,[-0.1 ; 2.9]$ & $2.5,[0.9 ; 5.1]$ & $2.1,[-0.8 ; 4.6]$ & $1.6,[-0.2 ; 4.8]$ \\
\hline P1, LS2 & $3.0,[-1.0 ; 7.9]$ & $2.6,[0.0 ; 6.0]$ & $5.6,[1.8 ; 15.5]$ & $3.7,[1.7 ; 9.3]$ \\
\hline P1, LS3 & $5.2,[1.2 ; 14.6]$ & $3.1,[0.8 ; 8.4]$ & $4.2,[0.8 ; 10.5]$ & $4.5,[1.8 ; 6.2]$ \\
\hline P2, LS1 & $0.6,[-1.2 ; 3.9]$ & $1.9,[0.0 ; 5.7]$ & $0.0,[-3.8 ; 3.0]$ & $1.4,[0.0 ; 4.5]$ \\
\hline P2, LS2 & $4.3,[0.1 ; 9.6]$ & $5.0,[2.0 ; 10.0]$ & $4.5,[-1.1 ; 11.6]$ & $4.9,[1.7 ; 9.2]$ \\
\hline P2, LS3 & $4.1,[0.3 ; 8.9]$ & $2.6,[0.4 ; 6.9]$ & $5.2,[0.5 ; 12.1]$ & $3.3,[0.8 ; 7.5]$ \\
\hline TD 0 to $\mathrm{TD}+30$ & $39.3,[18.9 ; 69.3]$ & $18.0,[4.5 ; 40.1]$ & $47.6,[22.1 ; 84.5]$ & $19.6,[5.6 ; 37.8]$ \\
\hline P1, LS1 & $17.4,[9.2 ; 27.2]$ & $11.9,[6.5 ; 23.8]$ & $20.7,[9.6 ; 35.2]$ & $11.7,[4.0 ; 21.0]$ \\
\hline P1, LS2 & $28.7,[12.5 ; 54.7]$ & $15.6,[1.5 ; 28.7]$ & $42.9,[21.7 ; 68.9]$ & $19.8,[8.4 ; 31.0]$ \\
\hline P1, LS3 & $25.7,[14.0 ; 61.5]$ & $7.7,[2.4 ; 18.0]$ & $44.5,[16.8 ; 78.3]$ & $12.3,[2.8 ; 33.7]$ \\
\hline P2, LS1 & $20.4,[7.7 ; 45.5]$ & $11.7,[2.9 ; 35.5]$ & $29.2,[12.6 ; 48.8]$ & $16.0,[6.7 ; 28.7]$ \\
\hline P2, LS2 & $49.9,[26.9 ; 81.0]$ & $25.2,[12.1 ; 49.0]$ & $60.6,[32.4 ; 115.3]$ & $26.7,[11.2 ; 49.1]$ \\
\hline P2, LS3 & $35.4,[16.3 ; 67.2]$ & $13.6,[1.0 ; 34.5]$ & $47.2,[21.7 ; 83.8]$ & $13.5,[2.2 ; 32.8]$ \\
\hline
\end{tabular}

357 When we express the milk losses relatively in \% compared to the expected production, the 
of the analysis. Figure 4 shows the median and quartiles of relative milk yield dynamics around the

TD. We observe that (1) the variability in relative milk losses in the IQ is much larger than in the contrast to NIQ, full recovery is not reached in most of the IQ within 30 days after the TD. The difference between relative milk losses in IQ and NIQ were significant on day $-3(p=0.046)$ and highly significant $(\mathrm{P}<0.001)$ from day -2 to day 30 relative to the TD.

Milk losses in perturbations. In 1878 out of the 2190 (85.7\%) IMI cases for which the IQ was identified, at least one quarter was perturbed at the TD. From these IMI cases, $31 \%$ had a

367 perturbation in only one quarter (the IQ), $19 \%$ in 2, $20 \%$ in 3 and $30 \%$ in all 4 quarters. In $35.3 \%$ of these IMI cases, the deviation in CMY was too small to meet the perturbation criteria used for that data, explaining the higher proportion of perturbations identified at quarter level compared to the cow level. When a perturbation was found in more than one quarter, the start DIM of these

371 perturbations was for $25 \%$ on exactly the same day and in $35 \%$ they started within 1 to 5 days from 372 each other. In 18\%, the start of the overlapping perturbations was between 5 to 10 days apart and 373 the remaining $22 \%$ started more than 10 days apart.

374 Figure 5 shows the absolute and relative milk losses per perturbation and the perturbation length 375 for the IQ (red) and the NIQ (blue). From this figure and as shown per lactation stage and parity 376 class in Table 6, we observe that the milk losses, both in absolute numbers and relatively, are higher 377 for the IQ than for the NIQ. This confirms the results of the analysis in a fixed window around the 378 TD. In 59\% of the IMI cases, the average absolute milk losses in NIQ, independent whether it 379 concerns a hind or front quarter is below $50 \mathrm{~kg}$, whereas this is true for only $32 \%$ of the IQ. 380 Expressed as relative losses (middle panel in Figure 5), 38\% of the IMI cases have NIQ milk losses 381 less than 20\%, whereas most IQ (32\%) lose between 20 to $30 \%$ compared to the expected 382 production. Also, the average perturbation length of the IQ is higher than in the NIQ, with for the 383 NIQ, 43\% of the perturbations shorter than 10 days, where this is only $12 \%$ for the IQ. 
384 Table 6 gives the milk losses of the perturbations at quarter level per lactation stage and parity

385 class. From this table, we see that the median losses in perturbations in the IQ are higher compared

386 to the NIQ for the same class, and that absolute losses in mid lactation (LS2) exceed the losses in

387 early and late lactation cases (LS1 and LS3 respectively). Moreover, when the IQ is a front quarter,

388 the absolute milk losses in perturbations are lower than when the IQ is a hind quarter. The relative

389 milk losses in the IQ, independent of the quarter position, are almost double the relative losses of

390 the NIQ.

391 Table 6. Absolute milk losses in perturbations associated with a IMI treatment in presumably infected (IQ) and non-

392 infected (NIQ) quarters, and the corresponding relative losses per day. The milk losses are expressed as the amount of

393 milk lost, and thus in positive numbers.

\begin{tabular}{|c|c|c|c|c|c|c|}
\hline & \multicolumn{4}{|c|}{ Absolute milk losses (kg) } & \multirow{2}{*}{\multicolumn{2}{|c|}{$\begin{array}{c}\text { Relative milk losses (\%) } \\
\text { IQ = front and hind } \\
\text { median, [Q25;Q75] }\end{array}$}} \\
\hline & \multicolumn{2}{|c|}{$\begin{array}{l}\text { IQ }^{4}=\text { front quarter } \\
\text { median, }[\mathrm{Q} 25 ; \mathrm{Q} 75]^{3}\end{array}$} & \multicolumn{2}{|c|}{$\begin{array}{l}\text { IQ = hind quarter } \\
\text { median, [Q25;Q75] }\end{array}$} & & \\
\hline & IQ & Average of NIQ ${ }^{5}$ & IQ & Average of NIQ & IQ & Average of NIQ \\
\hline Overall & $75.7,[35.5 ; 143.3]$ & $41.8,[19.3 ; 73.5]$ & $92.7,[45.3 ; 199.9]$ & $40.9,[20.2 ; 74.7]$ & $26.0,[19.0 ; 39.3]$ & $14.7,[8.7 ; 22.0]$ \\
\hline P1 $^{1}$, LS1 $^{2}$ & $22.0,[11.9 ; 49.0]$ & $18.8,[8.4 ; 35.8]$ & $31.6,[17.7 ; 59.8]$ & $18.7,[12.7 ; 28.3]$ & $28.0,[20.6 ; 37.2]$ & $15.1,[10.0 ; 23.0]$ \\
\hline P1, LS2 & $65.0,[33.2 ; 16.43]$ & 42.5, [19.6;64.7] & $97.7,[33.5 ; 145.8]$ & $36.0,[18.6 ; 61.8]$ & $24.9,[19.2 ; 32.8]$ & $12.1,[6.1 ; 20.8]$ \\
\hline P1, LS3 & $60.1,[32.6 ; 114.1]$ & $22.5,[8.4 ; 45.2]$ & $88.3,[37.7 ; 173.4]$ & $34.2,[15.1 ; 60.7]$ & $30.5,[20.4 ; 49.6]$ & $13.1,[7.1 ; 21.5]$ \\
\hline P2, LS1 & $30.5,[17.8 ; 49.5]$ & $25.7,[11.5 ; 48.1]$ & $40.7,[19.8 ; 74.0]$ & $26.2,[13.1 ; 46.5]$ & $24.5,[18.4 ; 31.8]$ & $16.5,[11.5 ; 21.4]$ \\
\hline P2, LS2 & $86.9,[42.1 ; 157.6]$ & $51.7,[30.1 ; 90.0]$ & $106.7,[58.2 ; 245.4]$ & $54.0,[28.0 ; 88.7]$ & $24.0,[18.4 ; 34.6]$ & $14.8,[9.6 ; 22.0]$ \\
\hline P2, LS3 & $78.1,[34.2 ; 151.0]$ & $39.4,[15.3 ; 67.9]$ & $101.5,[51.6 ; 211.7]$ & $36.5,[16.7 ; 66.0]$ & $28.2,[19.9 ; 44.2]$ & $14.7,[7.7 ; 22.6]$ \\
\hline
\end{tabular}

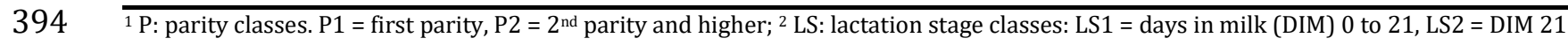

395 to $140, \mathrm{LS} 3=$ DIM 141 to $305 ;{ }^{3} \mathrm{Q}$ : quartiles, Q25 = first quartile, Q75 = last quartile; ${ }^{4} \mathrm{IQ}=$ presumably infected quarter; ${ }^{5} \mathrm{NIQ}=$

396 presumably non-infected quarters

\section{DISCUSSION}

399 Study design and objectives.

This study investigated milk losses associated with

400 treatments of IMI at cow and quarter level on farms with an AMS. Its approach is unique because

401 (1) we used commercial farm data from multiple dairy operations and 2 AMS brands, (2) analyzed

402 naturally occurring IMI and thus did not need to rely on controlled experiments limiting the

403 number of IMI cases for both feasibility and animal welfare issues, (3) investigated both the milk

404 losses at cow and at quarter level for different parities. The latter allowed to focus on differences 
between more and less severely affected quarters providing unique insights in both local and systemic effects of the infection caused by e.g. decreased feed intake.

407 We are aware that the use of commercial data and treatment registers involves a risk of including

408 false registrations and erroneous case identification in the analysis (Stevens et al., 2016).

409 Nevertheless, we reasoned that although the chance of missing IMI cases was fairly significant,

410 when a case was registered, the probability that an IMI had truly been treated was very high. The

411 results of this study demonstrate that in most IMI cases the milk production is indeed suppressed

412 around the recorded treatments. Because of the scale of the study and the high number of IMI cases

413 included, false registrations are assumed to minimally impact our results. Unfortunately, no

414 concrete data on false recordings to compare with are available in literature.

415 This study included data from over 30 commercial farms, nonetheless we could not compare them

416 because of significant differences in quality of the treatment registers and variability in the time

417 period for which milk production data and treatment registers were available. Accordingly, it was

418 not possible to make valid conclusions on the performance of individual farms and how milk

419 production is influenced by IMI. Still, the present joint analysis gives a valuable overview of the

420 impact of IMI on milk losses. A potentially interesting approach for comparing farms could be to

421 start from the quarter milk production data to identify QMY perturbations that are likely caused by

422 IMI. This way, a better idea of the IMI incidences and related milk losses could be obtained

423 including all the data available, and differences in farm performance can be studied without relying

424 on farmers' recording efforts. This is a promising path for future research.

425 Methodology. To study milk losses, an accurate estimation of the expected unperturbed

426 milk yield for a certain lactation is of utmost importance. Previous work showed that mastitis

427 influences the lactation curves, and therefore classical lactation models including the entire time

428 series cannot be used as such (Andersen et al., 2011). Several authors have recently developed 
methodologies that predict the unperturbed milk yield trajectory of a cow (Adriaens et al., 2020,

430 2021; Poppe et al., 2020; Ben Abdelkrim et al., 2021), from which the residuals can be used to

431 quantify deviations. The methodology that we developed previously has the advantage of being

432 applicable for QMY trajectories too, which allowed us to use an similar method at both the cow and

433 the quarter level in this study. Data-based estimation of unperturbed trajectories also has

434 disadvantages: when an infection permanently damages the udder and the milk yield never returns

435 to its original potential, it will not be corrected for by the methodology. This can explain the

436 differences in milk losses found here compared to those reported in studies applying a case-control

437 methodology (Heikkilä et al., 2018). Leitner et al. (2020) found altered histology of the mammary

438 gland caused by mastitis, potentially causing a more permanent lower production by the inflamed

439 udder quarters. Analysis of milk yield trajectories across different quarters and over lactations

440 might provide insight into the normal consistency and proportionalities between the QMY,

441 especially considering the high day-to-day variation (Forsbäck et al., 2010). This can help to better

442 understand how often permanent udder damage happens and what the effect is on the true milk

443 production. Penry et al. (2018) showed that there are significant associations between quarters for

444 individual milking events, but they did not consider longitudinal data characteristics. Nevertheless,

445 our earlier work (Adriaens et al., 2018) showed that both the peak yield and the persistency in

446 unperturbed milk yield curves differ across front and hind quarters, and that the variability in

447 quarter lactation shapes suggest that udder asymmetry and past infections may cause the expected

448 milk yield of the left and right udder quarters to be different.

449 True perturbations were discriminated from normal fluctuations in yield by using pre-set criteria

450 for length and depth of the model residuals, defined as the difference between the actual

451 production and the unperturbed lactation curves. Although these criteria may not capture very

452 subtle perturbations, previous research from Gröhn et al. (2004) and Hertl et al. (2014) showed

453 that IMI typically impact the milk yield well above the applied criteria. Including the perturbations 
454 in the analysis has the advantage that a better estimation of the true onset, duration and impact of

455 the infection on the milk yield dynamics can be obtained.

456 Milk losses at cow level. In this study we analyzed milk losses associated with an IMI

457 treatment both in a fixed window around the TD and in perturbations including the TD. Our results

458 correspond in general well to previously reported results, but because of unalike milk production

459 data frequencies and the selection procedure of IMI cases, direct comparisons were not possible.

460 Still, similar to other authors, we found a high variability in the milk losses associated with IMI. Part

461 of this variability can be attributed to differences in causal pathogen or clinical severity, which we

462 did not take into account in this study. Additionally, also differences in standard operating

463 procedures of the farmers for registering and treating cows can explain this observation (Heikkilä

464 et al., 2018). Many studies report effects of health status (Hertl et al., 2014), metabolic status (Gross

465 et al., 2020), persistency of the infection (White et al., 2010) and lactation stage (Heikkilä et al.,

466 2018) on the milk losses. In this study, we discriminated between lactation stage and parity classes,

467 but information on the pathogens was not available. Bar et al. (2008) found that both parity and

468 lactation stage indeed alter the effect of IMI on the milk losses, and their estimates were in a similar

469 order of magnitude as in this study, but estimated with a lower granularity of the data. Additionally,

470 Shim et al. (2004) demonstrated that the actual milk losses also depend on the treatments applied,

471 whereas Wilson et al. (2004) found an effect of simultaneous health problems other than mastitis.

472 For many IMI cases, our estimated milk losses were lower than those reported previously in

473 comparison with healthy herd mates, when milk yield measured at a lower frequency was used or

474 when the milk losses were calculated based on an increase in somatic cell count. In the study of

475 Wilson et al. (2004), the milk production losses were estimated around $600 \mathrm{~kg}$ for higher parity

476 cows being infected mid-lactation, which is higher than what we found with our analysis, probably

477 because we did not select a certain type of IMI neither looked across different health statuses that

478 might increase the milk losses. Based on their simulations, Van Soest et al. (2016) estimated milk 
losses for subclinical mastitis and clinical mastitis to be respectively 107 and $306 \mathrm{~kg}$. Given the

present variability, these estimates correspond rather well with what we found in this study.

481 Besides the differences in study design and case selection, other differences in milk losses can be explained by the different method by which we quantified the milk losses. In this study, the historical data and expected production dynamics of the treated cows themselves were used, and no comparisons were made with e.g. production levels of the herd or cows with similar parity and lactation stage, neither did we apply fixed percentages or formulas based on e.g. the cell count level. Our methodology might have the disadvantage that milk losses of cases in which damage of the udder tissue causes a permanent milk production drop are probably underestimated.

488 For monitoring purposes, analysis at cow level might not suffice because of (1) a dilution effect of non-infected quarters on the milk production, not allowing for the separation of local and systemic losses (Boland et al., 2013), and (2) compensatory effects between quarters that have been

491 demonstrated (Hamann and Reichmuth, 1990; Skarbye et al., 2018). A solution to this problem is

492 the analysis of milk losses at quarter level.

493 Milk losses at quarter level. Zhao and Lacasse (2008) described how IMI, besides the

494 systemic impact of the disease, also have a local effect on the mammary tissue due to the

495 inflammation reaction and the pathogen's toxins. This diversification opens opportunities for 496 studying the local and more general effects of the infection, but also for the development of new 497 monitoring tools using quarter level dynamics. With the increased use of AMS, these QMY data 498 become more and more available (Barkema et al., 2015). Indeed, this study demonstrated 499 differences in milk losses between IQ and NIQ, from already days before the TD. Based on the 500 differing number of quarters in which a perturbation was found, it appears that in milder cases, 501 part of the lost milk production in the IQ seems to be compensated in the NIQ, which is not captured 502 with the analysis at cow level. Additionally, the effect of the IMI on the IQ lasted much longer than 503 on the other quarters that only suffered from the systemic impact of the infection. We thereby 
504 confirmed the study of Paixão et al. (2017) who argued that also the adjacent quarters' health

505 status and milk composition is altered by mastitis, although with a lower severity. In the case-

506 control studies conducted by Gonçalves $(2018,2020)$, the causative pathogen was found to strongly

507 affect the ratio of quarter milk yields, next to the overall milk yield, in cows with subclinical

508 mastitis. For example, they reported daily milk losses between 0.8 and $1.3 \mathrm{~kg}$ per quarter (both

509 infected and non-infected), corresponding well to the results of our study.

$510 \quad$ Applications and future research.

In addition to a very detailed overview of the effect

511 of IMI on milk production at the cow level, this study also clearly reveals the potential of monitoring

512 the production dynamics at quarter level in the context of udder health. Many authors have already

513 shown that mastitis remains one of the most important diseases compromising sustainability of

514 dairy farms, and the economic impact is immense (Hogeveen et al., 2011; van Soest et al., 2016).

515 Milk losses are an important part of the udder health failure costs, and the development of

516 dedicated algorithms for monitoring recovery and cure has a huge potential to increase the relative

517 advantage of AMS systems. These algorithms can for example rely on a change in milk yield

518 dynamics, as demonstrated in this study. Stone (2020) argues that adoption of new PLF innovations

519 indeed depends on this relative advantage, their compatibility with current monitoring systems,

520 their complexity and their observability. Cabrera et al. (2020) reason that the key opportunities for

521 this lie in real-time continuous decision support based on data already available on many modern

522 dairy farms. For example, combining the methodology of the present study with e.g. online

523 modelling and prediction (Adriaens et al., 2018) and a synergistic control method (Huybrechts et

524 al., 2014) could provide the necessary leverage for implementation and adoption of a quarter-based

525 monitoring method maximizing the benefit of already available on-farm sensors. This can aid in

526 changing a farmer's attitude towards udder health management and antimicrobial use, with an

527 improved sustainability and a better socially accepted dairy production as a result (Deng et al.,

528 2020). 


\section{CONCLUSIONS}

530 This study confirms the high impact of IMI on the milk production of dairy cows in farms with an

531 AMS. Application of the methodology for estimating the unperturbed milk yield allowed to analyze

532 milk losses at the level of both the cow and the udder quarters. Next to the analysis of milk losses in

533 a fixed window around the treatment, also milk losses associated with perturbations including the

534 treatment day were considered. This allowed to estimate and take into account the true duration of

535 the perturbation. The analysis at quarter level showed clear differences between infected and non-

536 infected quarters, revealing the potential for developing novel udder health monitoring systems

537 that make use of commercially available on-farm data.

\section{ACKNOWLEDGEMENTS}

540 Ines Adriaens received funding from a KU Leuven postdoctoral mandate, grant number

541 PDM/19/132 (Leuven, Belgium). The data from this study were collected in the format of farm

542 software back-up files by the authors, and the resulting database is owned by the authors. We thank

543 dr. DVM. Sofie Piepers (Ghent University, Department of Reproduction, Obstetrics and Herd Health,

544 M-team and Mastitis and Milk Quality Research Unit, Belgium) for her help in the data collection

545 during the farm visits. Furthermore, this study is funded by VLAIO as an LA-trajectory (Brussels,

546 Belgium), grant number HBC.2016.0774. We thank Carmen Adriaens (Harvard Medical School and

547 Massachusetts General Hospital, Boston, USA) for her critical reading of the manuscript. The

548 authors have not stated any conflicts of interest. 
Ben Abdelkrim, A., T. Tribout, O. Martin, D. Boichard, V. Ducrocq, and N.C. Friggens. 2021. Exploring simultaneous perturbation profiles in milk yield and body weight reveals a diversity of animal responses and new opportunities to identify resilience proxies. J. Dairy Sci. 104:459-470.

Adriaens, I., I. van den Brulle, L. D’Anvers, J.M.E. Statham, K. Geerinckx, S. De Vliegher, S. Piepers, and B. Aernouts. 2021. Milk losses and dynamics during perturbations in dairy cows differ

Adriaens, I., N.C. Friggens, W. Ouweltjes, H. Scott, B. Aernouts, and J. Statham. 2020. Productive life with parity and lactation stage. J. Dairy Sci. 104:408-418. doi:10.3168/jds.2020-19195.

Adriaens, I., T. Huybrechts, B. Aernouts, K. Geerinckx, S. Piepers, B. De Ketelaere, and W. Saeys. 2018. Method for short-term prediction of milk yield at the quarter level to improve udder health monitoring. J. Dairy Sci. 1-10. doi:10.3168/jds.2018-14696.

Andersen, F., O. Østerås, O. Reksen, and Y.T. Gröhn. 2011. Mastitis and the shape of the lactation curve in Norwegian dairy cows. J. Dairy Res. 78:23-31. doi:10.1017/S0022029910000749. Y.H. Schukken. 2008. Effects of repeated episodes of generic clinical mastitis on mortality and

571 Barkema, H.W., M.A.G. von Keyserlingk, J.P. Kastelic, T.J.G.M. Lam, C. Luby, J.P. Roy, S.J. LeBlanc, G.P. Keefe, and D.F. Kelton. 2015. Invited review: Changes in the dairy industry affecting dairy cattle health and welfare. J. Dairy Sci. 98:7426-7445. doi:10.3168/jds.2015-9377.

574 Boland, F., L. O'Grady, and S.J. More. 2013. Investigating a dilution effect between somatic cell count 
and milk yield and estimating milk production losses in Irish dairy cattle. J. Dairy Sci. 96:14771484. doi:10.3168/jds.2012-6025.

Cabrera, V.E., J.A. Barrientos-Blanco, H. Delgado, and L. Fadul-Pacheco. 2020. Symposium review: 3866. doi:10.3168/jds.2019-17145.

Deng, Z., T.J.G.M. Lam, H. Hogeveen, M. Spaninks, N. Heij, M. Postema, T. van Werven, and G. Koop. 2020. Antimicrobial use and farmers' attitude toward mastitis treatment on dairy farms with automatic or conventional milking systems. J. Dairy Sci.. doi:10.3168/jds.2019-17960.

Forsbäck, L., H. Lindmark-Månsson, A. Andrén, M. Akerstedt, L. Andrée, and K. Svennersten-Sjaunja. 2010. Day-to-day variation in milk yield and milk composition at the udder-quarter level. J.

Gonçalves, J.L., C. Kamphuis, C.M.M.R. Martins, J.R. Barreiro, T. Tomazi, A.H. Gameiro, H. Hogeveen, and M. V. dos Santos. 2018. Bovine subclinical mastitis reduces milk yield and economic return. Livest. Sci. 210:25-32. doi:10.1016/j.livsci.2018.01.016.

Gonçalves, J.L., C. Kamphuis, H. Vernooij, J.P. Araújo, R.C. Grenfell, L. Juliano, K.L. Anderson, H.

Gröhn, Y.T., D.J. Wilson, R.N. González, J. a Hertl, H. Schulte, G. Bennett, and Y.H. Schukken. 2004. Effect of pathogen-specific clinical mastitis on milk yield in dairy cows. J. Dairy Sci. 87:3358- 
Hamann, J., and J. Reichmuth. 1990. Compensatory milk production within the bovine udder: effects of short-term non-milking of single quarters. J. Dairy Res. 57:17-22.

600 doi:10.1017/S002202990002656X.

Heikkilä, A.M., E. Liski, S. Pyörälä, and S. Taponen. 2018. Pathogen-specific production losses in bovine mastitis. J. Dairy Sci. 101:9493-9504. doi:10.3168/jds.2018-14824.

Hertl, J. a, Y.H. Schukken, F.L. Welcome, L.W. Tauer, and Y.T. Gröhn. 2014. Pathogen-specific effects on milk yield in repeated clinical mastitis episodes in Holstein dairy cows. J. Dairy Sci.

Hogeveen, H., K. Huijps, and T.J.G.M. Lam. 2011. Economic aspects of mastitis: new developments. N.

Huybrechts, T., K. Mertens, J. De Baerdemaeker, B. De Ketelaere, and W. Saeys. 2014. Early warnings from automatic milk yield monitoring with online synergistic control. J. Dairy Sci. 97:3371-81.

Leitner, G., S.E. Blum, O. Krifuks, N. Edery, and U. Merin. 2020. Correlation between milk doi:http://dx.doi.org/ 10.3168/jds.2013-6913.

Paixão, M.G., L.R. Abreu, R. Richert, and P.L. Ruegg. 2017. Milk composition and health status from mammary gland quarters adjacent to glands affected with naturally occurring clinical mastitis. and milk production rate in an automatic milking system. J. Dairy Sci. 101:1-10. doi:10.3168/jds.2016-12196.

Poppe, M., R.F. Veerkamp, M.L. van Pelt, and H.A. Mulder. 2020. Exploration of variance, 
autocorrelation, and skewness of deviations from lactation curves as resilience indicators for breeding. J. Dairy Sci. 103:1667-1684. doi:10.3168/jds.2019-17290.

623 Shim, E.H., R.D. Shanks, and D.E. Morin. 2004. Milk loss and treatment costs associated with two 624 treatment protocols for clinical mastitis in dairy cows. J. Dairy Sci. 87:2702-2708. doi:10.3168/jds.S0022-0302(04)73397-4.

Skarbye, A.P., M.A. Krogh, and J.T. Sørensen. 2018. The effect of individual quarter dry-off in

van Soest, F.J.S., I.M.G.A. Santman-Berends, T.J.G.M. Lam, and H. Hogeveen. 2016. Failure and preventive costs of mastitis on Dutch dairy farms. J. Dairy Sci. 99:8365-8374.

Stevens, M., S. Piepers, K. Supré, J. Dewulf, and S. de Vliegher. 2016. Quantification of antimicrobial consumption in adult cattle on dairy herds in Flanders, Belgium, and associations with udder

Stone, A.E. 2020. Symposium review: The most important factors affecting adoption of precision dairy monitoring technologies. J. Dairy Sci. 103:5740-5745. doi:10.3168/jds.2019-17148.

White, L.J., Y.H. Schukken, B. Dogan, L. Green, D. Döpfer, M.J. Chappell, and G.F. Medley. 2010. Modelling the dynamics of intramammary E. coli infections in dairy cows: understanding 
weights. J. Dairy Sci. 87:2073-84. doi:10.3168/jds.S0022-0302(04)70025-9.

645 Wood, P. 1967. Algebraic model of the lactation curve in cattle. Nature 216:164-165.

646 Zhao, X., and P. Lacasse. 2008. Mammary tissue damage during bovine mastitis: causes and control.

$647 \quad$ J. Anim. Sci. 86:57-65. doi:10.2527/jas.2007-0302.

648

649 
651 Figure 1. Visualization of the different steps to obtain the unperturbed milk production curves at

652 quarter level. The upper panel shows the transformed quarter milk yields (QMYt), the data

653 excluded because of outlying values above 4 times the median average distance (MAD) from a 18

654 measurement median window smoothing (grey solid lines, green squares), the measurements

655 excluded because they were below the threshold in estimating the unperturbed curves (orange

656 dots), and the final model ULCF (blue solid line). The middle panel shows the raw QMY data and

657 retransformed ULCF. The lower panel shows the relative residuals (\% per day) from this model, the

658 median smoothed relative residuals and the 80\% threshold (red solid line) applied to identify

659 perturbations.

661 Figure 2. Median, 25 and 75 percentiles of the relative milk yield losses expressed in \% milk losses

662 over time in a fixed window of 36 days around the first treatment (red vertical line, day 0 of

663 treatment) in different lactation stage and parity categories. The milk losses are shown in negative

664 figures representing the true direction of the change during intramammary infections.

666 Figure 3. Frequencies of perturbation length around treatments for intramammary infections (IMI)

667 in different lactation stages. The red dashed line shows the perturbations above and below 30 days

668 of length.

670 Figure 4. Relative milk losses in the presumably infected (IQ) and the average of the non-infected

671 quarters (NIQ) in the 36 days around treatment. On day -3 , the asterisks indicate that the difference 
bioRxiv preprint doi: https://doi.org/10.1101/2021.01.04.425263; this version posted January 5, 2021. The copyright holder for this preprint (which was not certified by peer review) is the author/funder, who has granted bioRxiv a license to display the preprint in perpetuity. It is made available under aCC-BY-NC-ND 4.0 International license.

672 between IQ and NIQ is significant with $\mathrm{P}<0.05$, while on day -2 to 30 , the difference is significant

673 with $\mathrm{P}<0.001$

674

675 Figure 5. Distributions of milk losses and perturbation length in presumably infected (IQ) and non-

676 infected quarters (NIQ). 

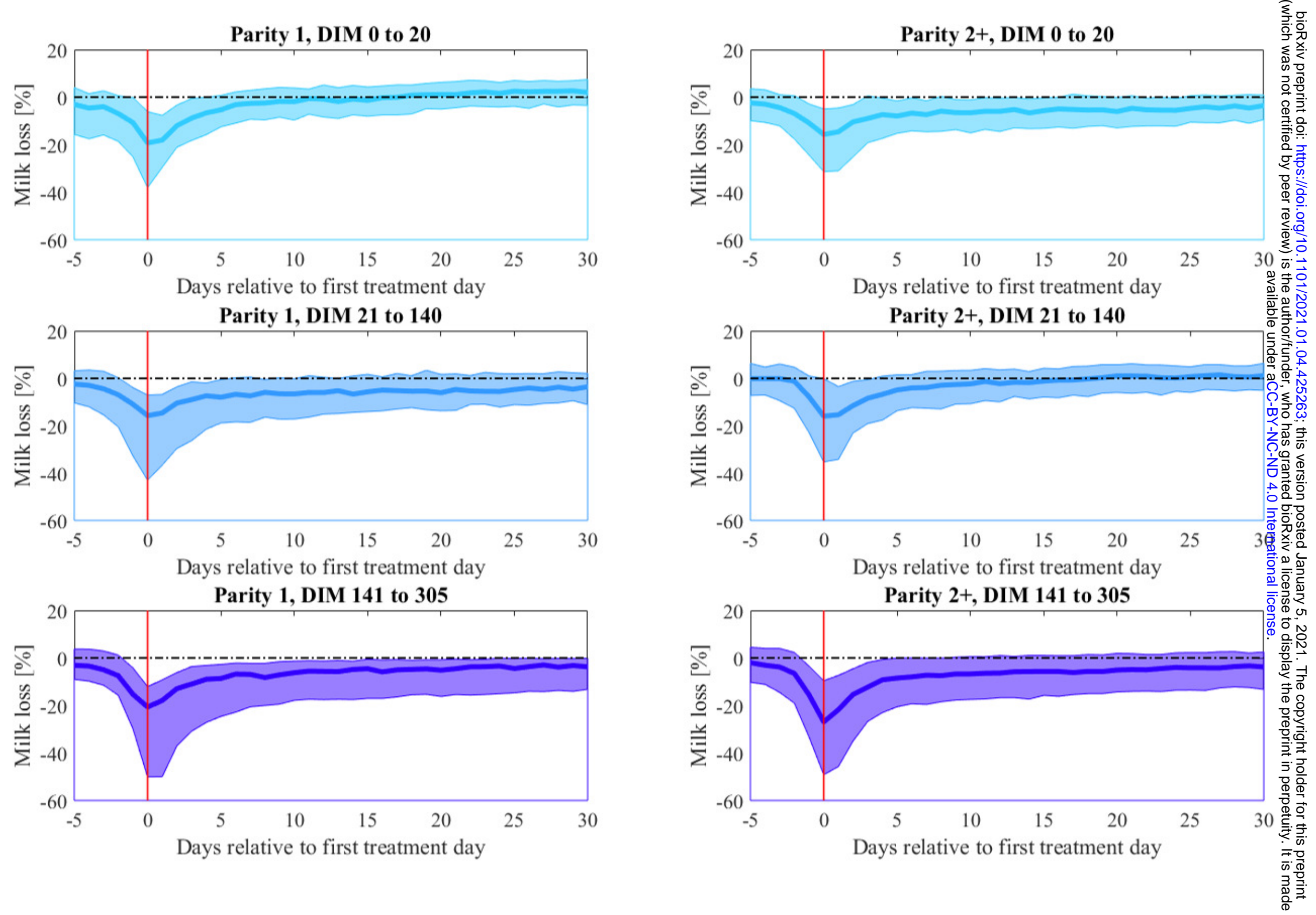


\section{Perturbation length, DIM 0 - 20}
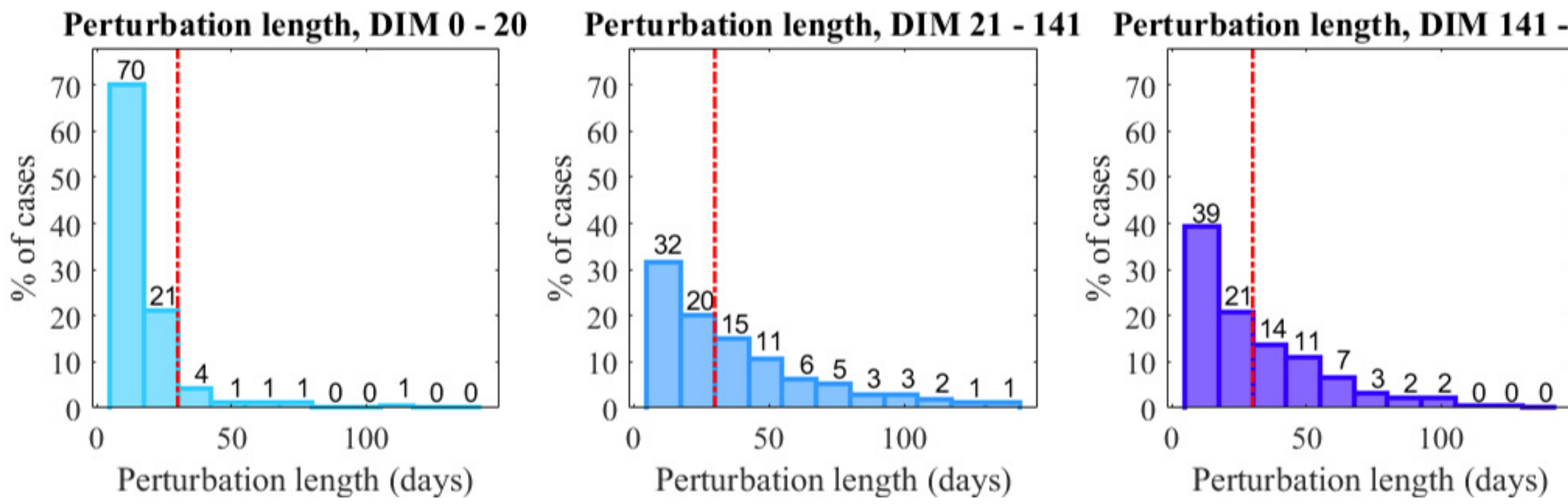


\section{Relative milk loss in IQ and NIQ}

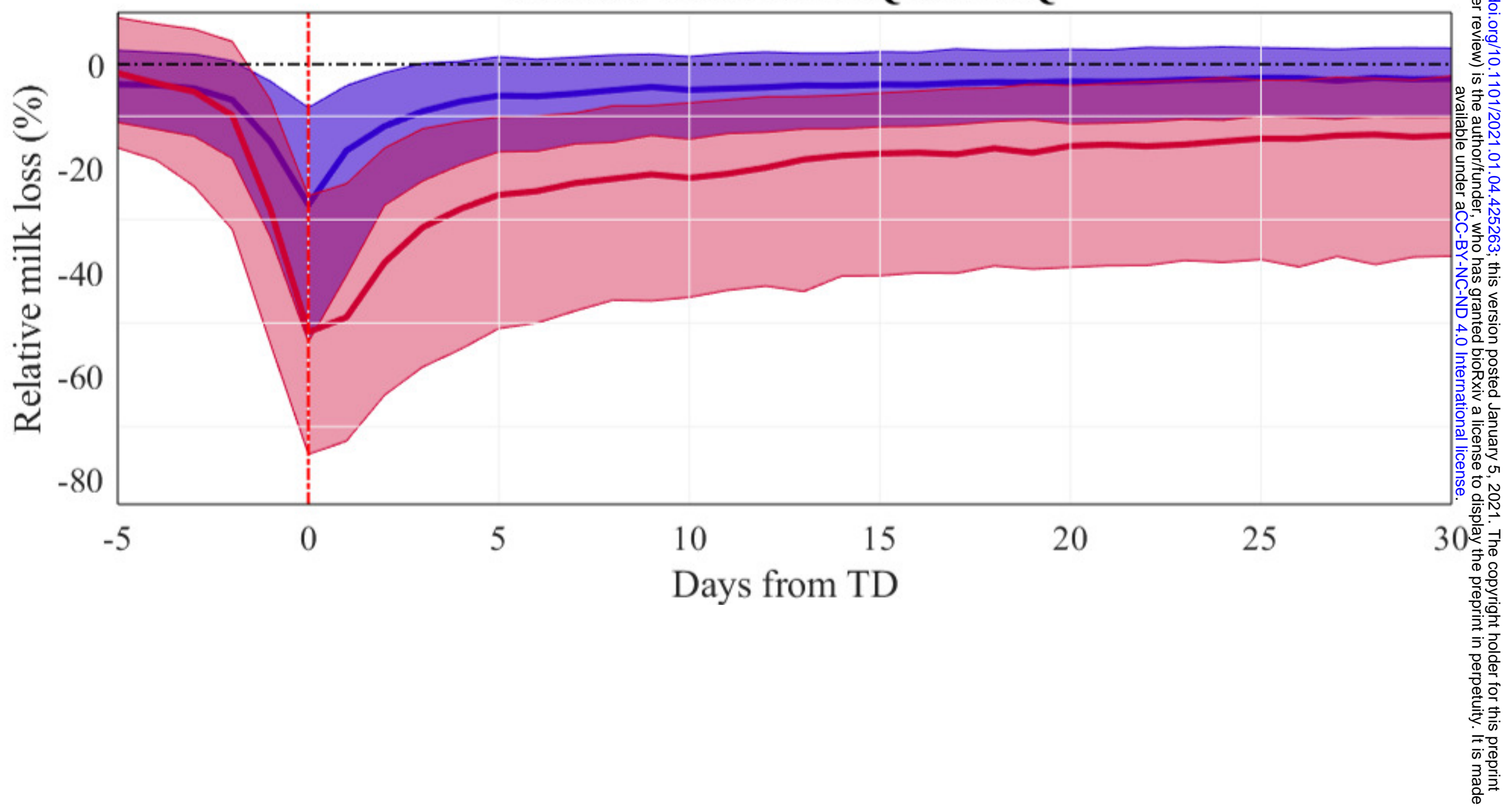



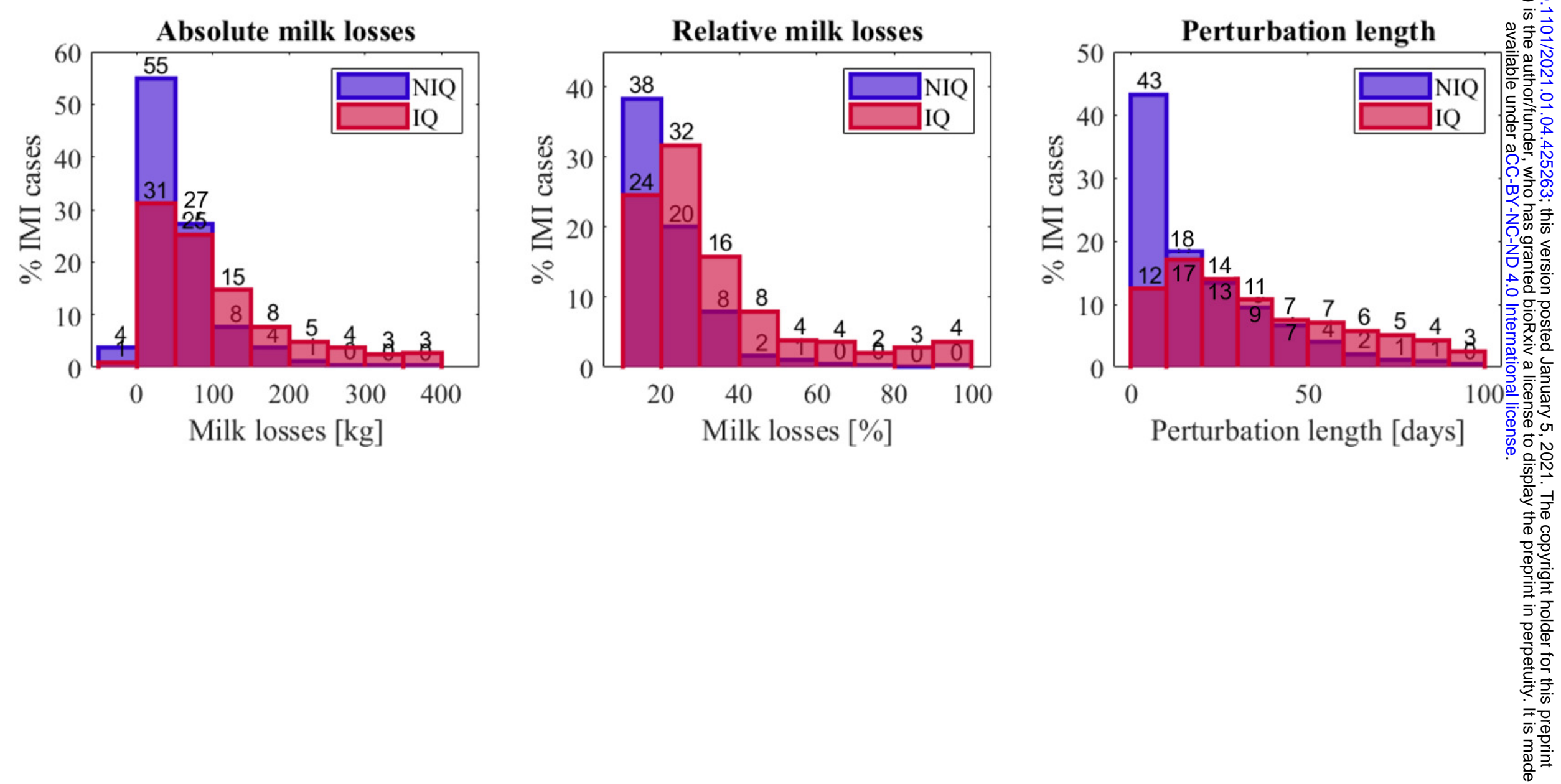

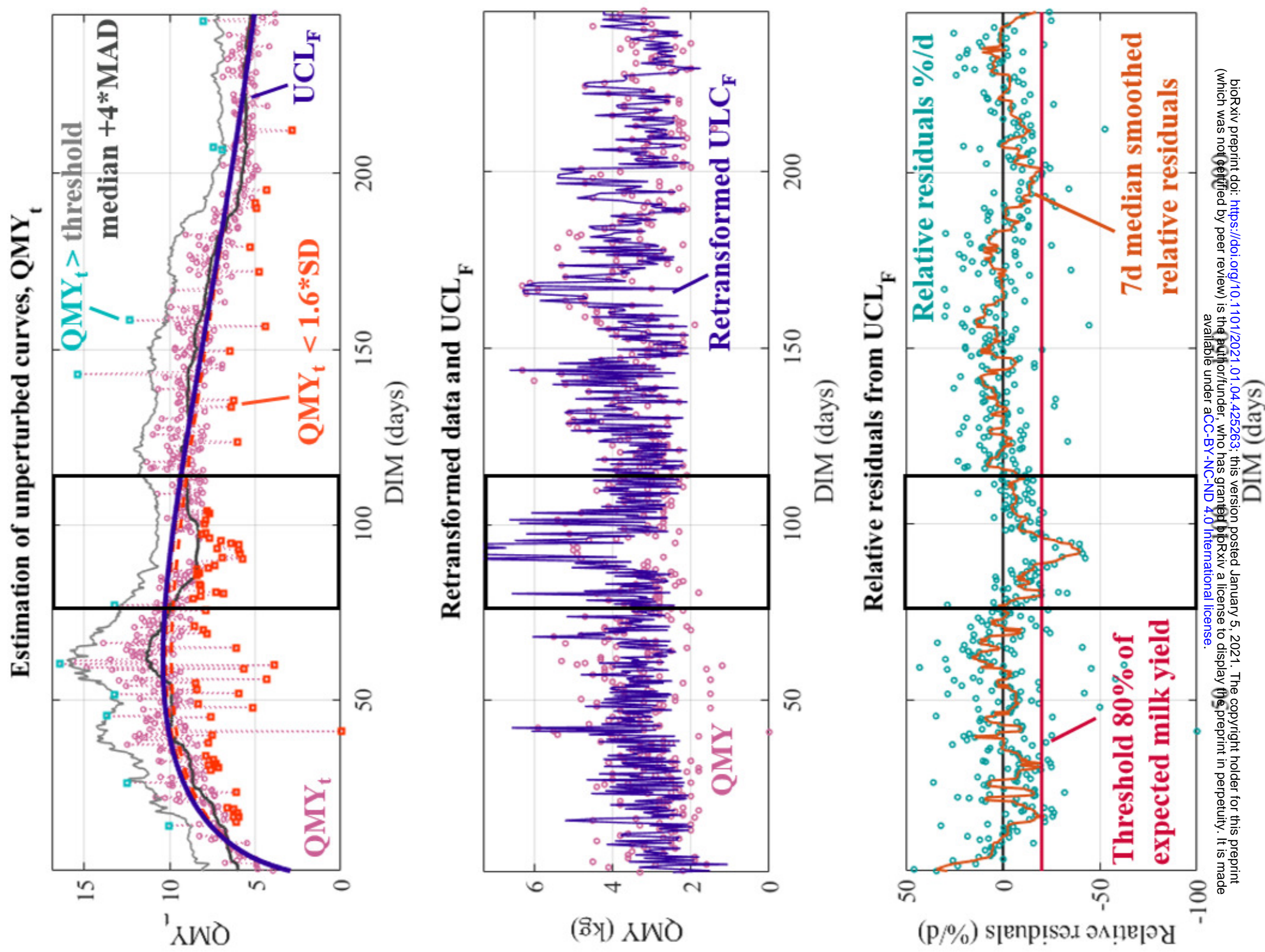